\title{
Lucía de Siracusa: Santa patrona de las enfermedades de los
} ojos

\section{Lucy of Syracuse. Patron saint of eye disorders}

Carlos Ortiz-Hidalgo*

Departamento de Anatomía Patológica, Hospital y Fundación Médica Sur, Departamento de Biología Celular y Tisular, Universidad Panamericana, Ciudad de México, México

\section{Resumen}

Santa Lucía (la Virgen mártir de Siracusa) es reconocida como la patrona de aquellos que sufren de ceguera y enférmedades oculares. Lucía fue acusada de ser cristiana y fue martirizada en Siracusa en el año 304 durante la persecución de Diocleciano. Lucía había consagrado su virginidad a Dios, sin embargo, su madre, Eutiquia, le arregló matrimonio coß̊ un joven, y Lucía se negó a casarse con él y fue castigada por el gobernador Pascasio, quien ordenó a los guardias quie le quitaran los ojos. Esta es la razón por la cual esta santa es la patrona de las enfermedades oculares. Cuando su cüerpo estaba preparado para ser enterrado, se descubrió que sus ojos habían sido milagrosamente restaurados. En las pinturas, Lucía es mostrada con los ojos en un plato dorado y también sosteniendo la rama de palma, que simboliza el martirio y la victoria sobre el mal. Su fiesta se celebra el 13 de diciembre.

Palabra clave: Santa Lucía. Patrona de las enfermedades de los ojos.

\section{Abstract}

Saint Lucy (the virgin martyr of Syracuse) is recognized today as the patroness of those who suffer from blindness andbeye ailments. Lucy was accused of being a Christian, and was executed in Syracuse, in 304 during the Diocletianic Persecution. Lucy had consecrated her virginity to God; however, her mother Eutychia arranged Lucy's marriage to a young man. Lucy refused to marry him and was punished by governor Paschasius who ordered the guards to remove her eyes. This is the reason why Lucy is the patron saint of eye illnesses. When her body was being prepared for burial, it was discoveredthat her eyes had been miraculously restored. In paintings, Lucy is frequently shown holding her eyes on a golden dish. She-also holds the palm branch, a symbol of martyrdom and victory over evil. Her feast day is December $13^{\text {th }}$.

Key words: Saint Lucy. Patroness of the blind.

\section{Introducción}

De todos los santos que han estado vinculados con enfermedades de los ojos, Lucía de Siracusa ha sido la más popular (Tabla 1). Santa Lucía es la patrona de los ciegos y abogada de problemas de la vista, y muchos pacientes aquejados con estos problemas imploran a esta santa para pedirle mediación para su mal'. Lucía, además, es patrona de aquellos pacieñtes

Correspondencia:

${ }^{*}$ Carlos Ortiz-Hidalgo

Av. Puente de Piedra, 150

Col. Toriello Guerra, Del. Tlalpan

Fecha de recepción: 26-04-2020

C.P. 14060 , Ciudad de México

E-mail: ortizhidalgocarlos@gmail.com DOI: 10.24875/RMO.M20000152

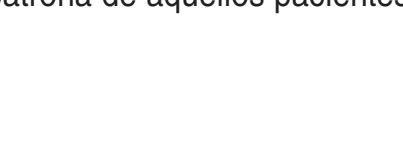

Disponible en internet: 11-01-2021 Rev Mex Oftalmol. 2021;95(1):28-34 www.rmo.com.mx (http://creativecommons.org/licenses/by-nc-nd/4.0/). 
Tabla 1. Algunos santos patrones protectores de las enfermedades de los ojos

\begin{tabular}{|c|c|}
\hline Santo & Fecha \\
\hline Santa Lucía de Siracusa & $\begin{array}{l}(283-304) \\
\text { Fiesta, } 13 \text { de diciembre }\end{array}$ \\
\hline Beata Margarita de Cittá di Castello & (1287-12 abril de 1320) \\
\hline San Ansfrido de Utrecht & (? -3 de mayo de 1010) \\
\hline San Herveo (Hervé) de Bretaña & $\begin{array}{l}\text { (c. } 521-556 \text { ) } \\
\text { Fiesta: } 17 \text { de junio }\end{array}$ \\
\hline San Audomar (Omer) de Therouanne & $\begin{array}{l}\text { (? -670) } \\
\text { Fiesta: } 9 \text { de septiembre }\end{array}$ \\
\hline San Eustasio de Luxeuil & $\begin{array}{l}\text { (c. } 560 \text {-c. } 626 \text { ) } \\
\text { Fiesta: } 2 \text { de abril }\end{array}$ \\
\hline San Salomón (Salaün) de Bretaña & $\begin{array}{l}\text { (? -874) } \\
\text { Fiesta: } 25 \text { de junio }\end{array}$ \\
\hline San Ulrich de Zell & $\begin{array}{l}\text { (1029-1093) } \\
\text { Fiesta: } 14 \text { de julio }\end{array}$ \\
\hline Santa Godeleva de Gistel & $\begin{array}{l}\text { (c. } 1049-1070 \text { ) } \\
\text { Fiesta: } 6 \text { de julio }\end{array}$ \\
\hline Santa Maxellendis de Caudry & $\begin{array}{l}\text { (? -670) } \\
\text { Fiesta: } 13 \text { de noviembre }\end{array}$ \\
\hline Santa Odilia (Otilia) de Alsacia & $\begin{array}{l}\text { (662-720) } \\
\text { Fiesta: } 13-14 \text { de diciembre }\end{array}$ \\
\hline
\end{tabular}

\section{Caracteristicas/patronazgo}

Protectora de la vista, deriva de la cercanía etimológica dề nombre griego "Lucía" con el término latino lux = luz. También protectora de electricistas.

Era ciega de nacimiento. Beatificada en 1609 por el Papa Pablo V.

Al final de sus días quedó ciego, pero en el momento de sú muerte vio una luz brillante en su habitación.

Era ciego de nacimiento.

Perdió la vista al final de su vida.

Invocado para los trastornos de la vista.

Se dice que curó a Santa Sadalberga de la ceguera y que invocándolo a través de oraciones puede curar la ceguera.

Fue cegado antes de martirizarlo y muerto en la iglesia por sus adversarios.

Dos años antes de su muerte perdió la vista.

Venerada por la curación de Edith, una niña ciega.

Es abogada contra los males de la vista.

Nació ciega, pero obtuvo la visión al ser bautizada. Otilia = hija de la luz con enfermedades de la garganta y también de los electricistas, modistas, campesinos, chóferes, afiladores, cortadores, cristaleros, escritores y de diversas ciudades como Siracusa, Venecia, Pedro del Monte en Burgos, Santa Lucía en Panamá, Mossoró en Brasil y Moche en Perú, entre muchas otras ${ }^{1,2}$.

Lucía, cuyo nombre significa luz (latín, lucius/lux), fue una de las once santas reconocidas oficialmente desde el año 600. Ella fue una mártir cristiana que padeció el martirio durante la gran persecución de los cristianos por el emperador romano Diocleciano (Gaius Aurelius Valerius Diocletianus Augustus) (244-311) ${ }^{1}$. Su fiesta se celebra en al menos 20 ciudades italianas y en diferentes localidades del mundo, y hay numerosas iglesias dedicadas a ella. Su festividad es el 13 de diciembre tanto en la iglesia católica como en la anglicana, la ortodoxa y la luterana (Lucía es la única santa aceptada por la iglesia luterana, excepto San Esteban, cuya celebración ha sido absorbida por la celebración de Santa Lucía). En el siglo VI, Lucía ya era venerada, y el Papa Gregorio Magno (San Gregorio) (c. 540-604) fue quien la incluyó en el canon de la Misa, agregó oraciones y cantos especiales (canto gregoriano sacramental) y también la anexó en el libro litúrgico de -los ritos latinos de la Iglesia católica (el antifonario). Asimismo, San Gregorio le puso el nombre de êsta santa a dos conventos que él fundó en el año 590 \% La historia de la vida de Santa Lucía se remonta a ưna narración del siglo V, relatada en el Acta de los Mártires (Acta Martyrum $)^{1,2}$.

\section{Santa Lucía y el martirio}

Santa Lucía nació en el año 283, en el seno de ưna familia respetada y próspera, en Siracusa, ciứdad situada en la costa sureste de la isla de Sicilia $S u$ padre, llamado Lucio, murió cuando ella tenía 5 ẫos y su madre, Eutiquia, fue quien la educó en la fe-cristiana. Siendo muy joven, Lucía decidió consagrar su vida a Dios y rechazó la propuesta de matrimonió de varios jóvenes. Eutiquia estaba muy enferma, con sangrados constantes, y sabía que los médicos nê le habían dado ninguna esperanza para su recuperación. Por esto, las dos peregrinaron 67 kilómetros, de 
Siracusa hacia la ciudad de Catania, al santuario de Santa Águeda (quien había sido martirizada 52 años antes), para pedirle que sanara su mal. Al llegar a la tumba pasaron toda una noche orando, y cuentan que, mientras dormían, Águeda se apareció rodeada de ángeles y le dijo a Lucía que ella misma poseía dones curativos y que su madre quedaría curada por su fe. Este pasaje fue ilustrado por el pintor veneciano Jacobello Del Fiore (1370-1439) en la pintura titulada Santa Lucía ante la tumba de Santa Águeda (Fig. 1). Águeda le dijo a Lucía que, así como Cristo había ayudado a la ciudad de Catania, él ayudaría a Siracusa ("Sicut per me civitas Catanensium sublimatur a Christo, ita per te Syracusana civitas decorabitur»), y, en ese instante, su madre quedó curada ${ }^{3}$. De regreso a Siracusa, Lucía pidió de favor a su madre que jamás la entregara en matrimonio, pues ella quería consagrar su vida a Dios, y que repartiera todos sus bienes entre los pobres. Eutiquia accedió a su petición y ambas empezaron a distribuir sus pertenencias entre los más desfavorecidos. Pero, pasado el tiempo, su madre, sin explicación alguna, obligó a Lucía a aceptar en matrimonio a un joven pagano al cual Lucía rechazó2,4. El joven, disgustado, la acusó ante el procónsul de Siracusa de ser cristiana, en tiempos de la gran persecución de cristianos por el emperador Diocleciano. El cónsul Pascacio ordenó que Lucía fuera conducida ante un juez, quien la presionó para que desistiera de la fe cristiana. Entonces Lucía respondió: «Es inútil que insista. Jamás podrá apartarme del amor a mi Señor Jesucristo... Sacrificio puro delante de Dios es visitar a las viudas, los huérfanos y los peregrinos que pagan en la angustia y en la necesidad, y ya es el tercer año que me ofrecen sacrificios a Dios en Jesucristo entregando todos mis bienes». Furioso por su respuesta, el cónsul dispuso que la llevaran a un prostíbulo para que la violaran, a lo cual Lucía exclamó: «El cuerpo queda contaminado solamente si el alma está consciente». Cuentan que Santo Tomás de Aquino (1224/12251274), considerado una de las mayores figuras de la teología sistemática, elogiaba estas respuestas de Santa Lucía.

Para conducirla al prostíbulo, los soldados le amarraron las manos y los pies con cuerdas, pero por más esfuerzos que hacían no podían moverla. La leyenda indica que, mientras ella discutía con el cónsul, el Espíritu Santo la tornó tan pesada que ni siquiera varios bueyes consiguieron moverla. Al enterarse de lo sucedido, el cónsul ordenó someterla a suplicio con aceite hirviendo, pero no logró hacerla desistir. A menudo, esta escena se representa en pinturas como

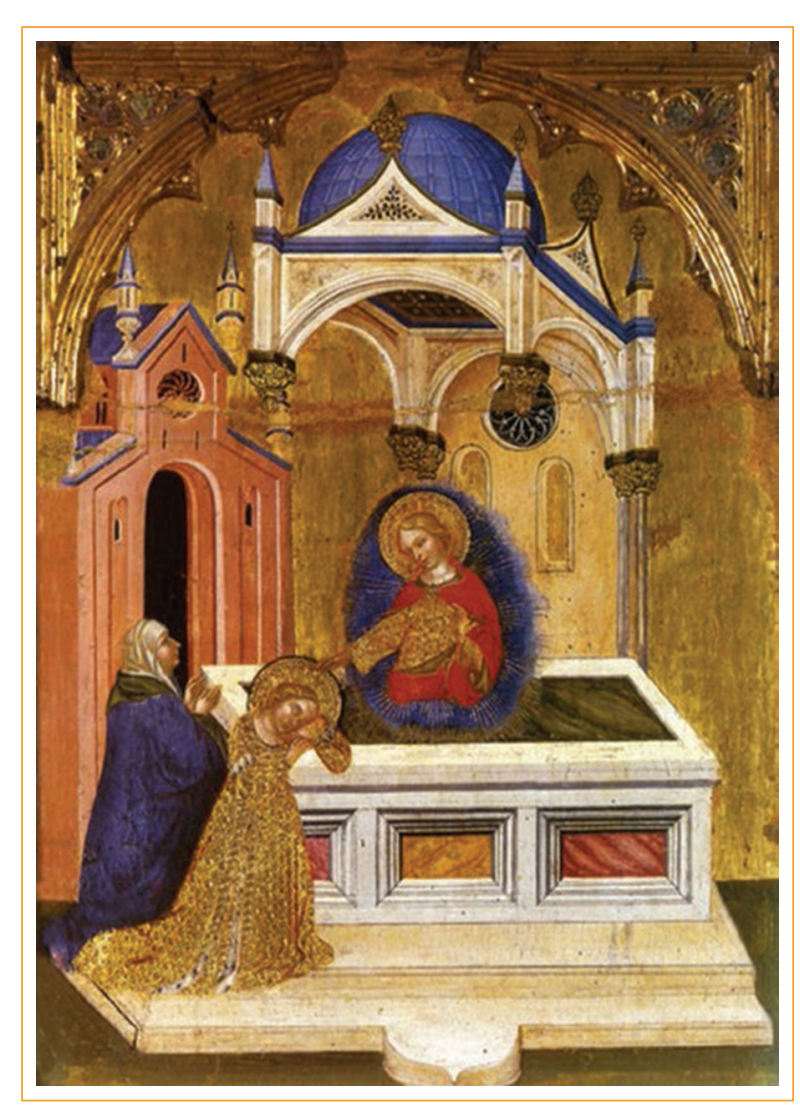

Figura 1. Santa Lucía ante la tumba de Santa Águedầ Autor: Jacobello Del Fiore. Museo Cívico, Fermo, Italia.

la titulada El martirio de Santa Lucía, realizada en 1596 por Leandro (dal Ponte) Bassano (1557-1622), o la-de Giovanni di Bartolomeo Cristiani (1340-1398), titufada Santa Lucía resistiendo los esfuerzos para moverla; ambas se encuentran en la Abadía de San Giơpgio Maggiore, en Venecia (Fig. 2).

El cónsul, al enterarse de lo sucedido, y convencido de que Lucía era una bruja, ordenó que la quemàran en la hoguera, pero, después de arder y consumirse toda la leña, Lucía estaba íntegra. Este pasaje đfue pintado en temple sobre madera (la técnica pictorica más antigua que se conoce) por el pintor catălán Bernat Martorell (1400-1452), y se titula Martirio de Santa Lucía en la hoguera (c. 1435) (Fig. 3). Al verque Lucía no la dañaba el fuego, ordenó que le sacarañlos ojos, pero ella misma inmediatamente se los colöcó. Finalmente fue decapitada, lo que sucedió el día 13 de diciembre del año $304^{1,4}$. Una narración mediêval indica que fue en la tribuna ante el procónsul donde le quitaron los ojos, pero, aun sin ellos, Lucía pudo seguir viendo ${ }^{4}$. Otros afirman que, después que le arrancāran los ojos, Dios le concedió unos nuevos, aún más 


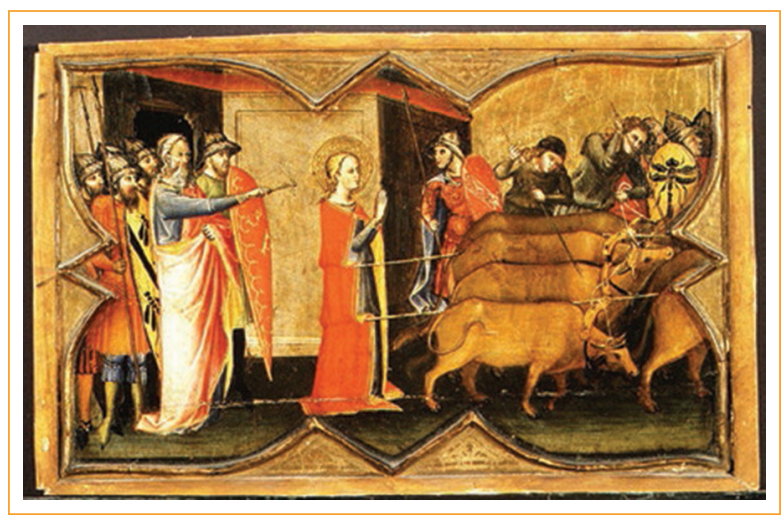

Figura 2. Santa Lucía resistiendo los esfuerzos para moverla. Autor: Giovanni di Bartolommeo Cristiani. Museo Metropolitano de Arte. Nueva York, EE. UU.

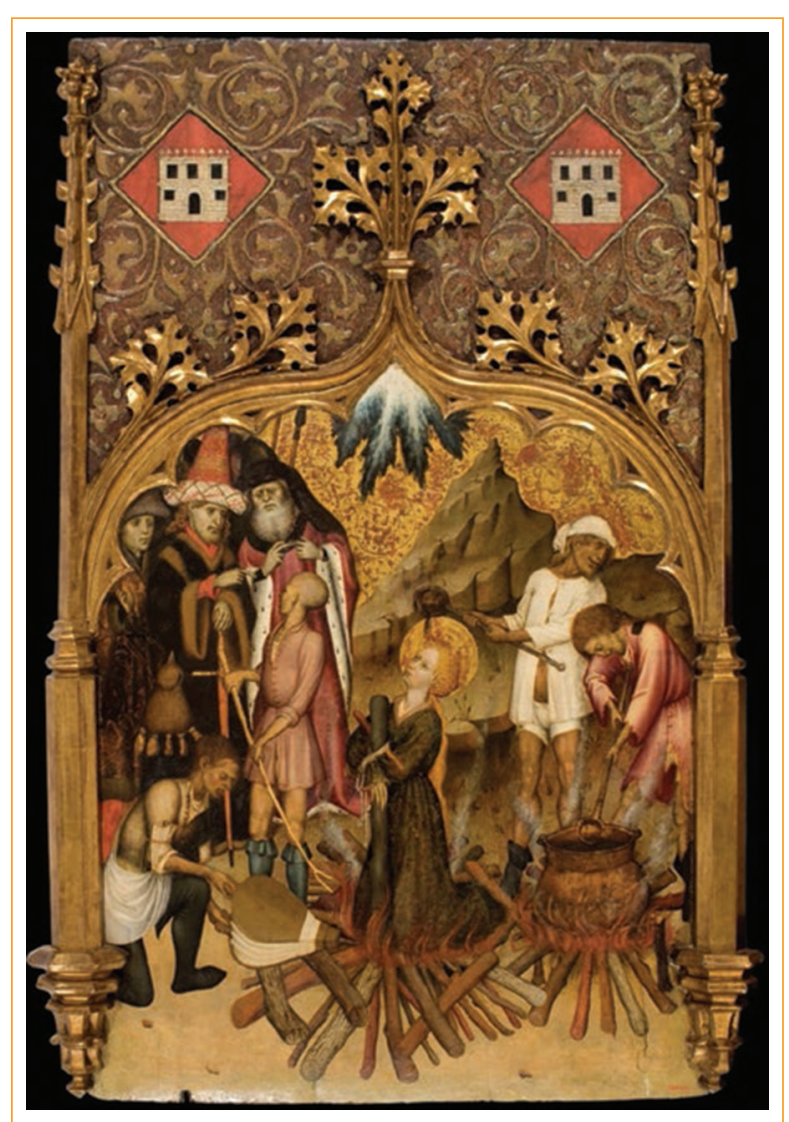

Figura 3. Martirio de Santa Lucía en la hoguera. Autor: Bernat Martorell. Por cortesía del Museu Nacional d'Art de Catalunya, Depósito de la Generalitat de Catalunya, Fundación Torres, 1995. (C) Museu Nacional d'Art de Catalunya, Barcelona (2020).

hermosos que los que tenía antes ${ }^{4}$. Dicen, también, que le atravesaron la garganta con una lanza. Finalmente Lucía fue sepultada en el mismo lugar

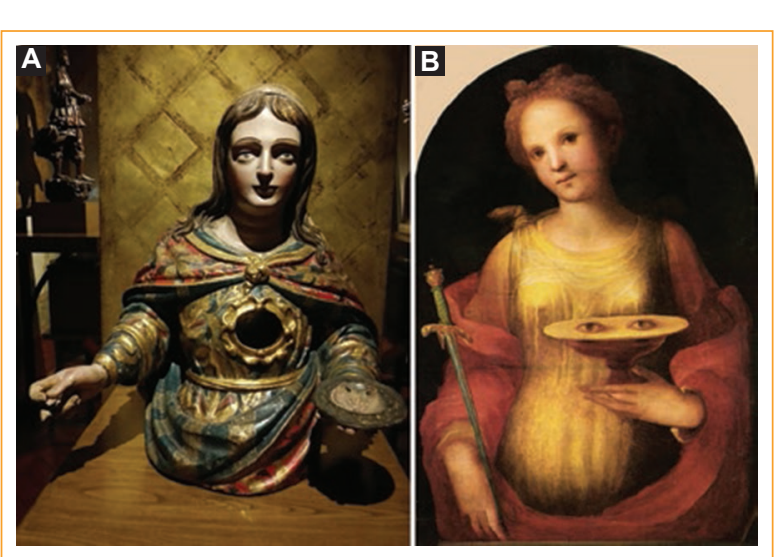

Figura 4. A: Escultura de Santa Lucía en madera. Museo de las Culturas de Oaxaca/Ex Convento de Santo Domingo de Guzmán. B: Santa Lucía. Autor: Domenico di Pace Beccafumi. Pinacoteca Nazionale di Siena. En ambas figuras, Santa Lucía muestra los ojos sobre una bandeja.

donde en el año 313 se construyó un santuario dedicado a ella. Relatan que se arrodilló para la decapitación y aun después del evento, Lucía siguió exhortando a los fieles para que antepusieran los deberes con Dios $^{1,2}$.

Otra leyenda cuenta que fue la belleza de los ôjos de Lucía la que no permitía descansar a uno de pretendientes, por lo que ella se los arrancó y sēlos envió en un plato². Lleno de remordimiento y sorprendido por la valentía, el pretendiente se convirtió al cristianismo. Al igual que hay representaciones pictóricas donde Santa Águeda está portando sus sẹnos amputados en una bandeja, así, Lucía aparece en algunos grabados medievales con sus ojos sobre un plato (Figs. 4 A y B) $)^{5}$.

Una coincidencia más entre Santa Lucía y Sânta Águeda es que, en el año 1039, por orden del geñeral bizantino Georgios Maniaces (?-1043), los cuerpos de ambas fueron trasladados a Constantinopla para alejarlas de la invasión árabe a Siracusa. Pocos años después, el cuerpo de Santa Águeda fue devuelto a Catania, pero no fue sino hasta el año 1204, durănte la cuarta cruzada, que el duque de Venecia, Enrico Dandolo (1107-1205), encontró los restos de Sănta Lucía en Constantinopla y los llevó al monasterio de San Jorge, y en 1280 los trasladó a Venecia, donde actualmente se encuentran en un sarcófago de crìstal bajo el altar, en la iglesia de los santos Jeremías y Lucía (Chiesa dei Santi Geremia e Lucia), situadá en la plaza de San Jeremías en Venecia. En 1955, por deseo del entonces Cardenal Angelo Giuseppe Roncalli 


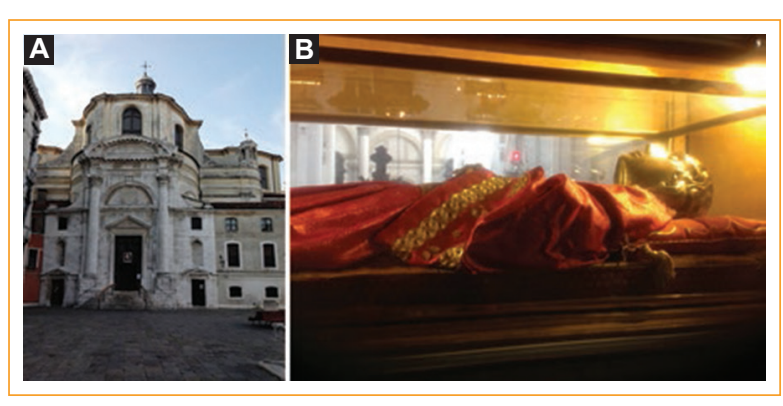

Figura 5. A: Fachada del templo de los santos Jeremías y Lucía en Venecia. B: Máscara de plata de Santa Lucía.

(1881-1963) (futuro Juan XXIII, «El buen papa Juan»), el rostro de la santa fue cubierto con una máscara de plata (Figs. $5 \mathrm{~A}$ y B). Los restos de la santa fueron trasladados a esta iglesia en 1861, cuando la originalmente dedicada a ella fue demolida para construir la estación de tren, que lleva por ello su mismo nombre: Stazione di Venezia Santa Lucia. Como Lucía era siciliana, hubo muchas presiones para que la santa fuera devuelta a su lugar de nacimiento, y los sicilianos se han tenido que conformar con un dedo de ella que se venera en su iglesia de Santa Lucía en Siracusa. Cuentan que un devoto siciliano llegó a Venecia y pidió permiso para besar el cuerpo de la santa y en vez de darle un beso le dio una mordida al dedo y se lo llevó escondido dentro de la boca ${ }^{1,2}$. Se rumorea que fue la mafia siciliana quien, el domingo 8 de febrero de 1981 a las 9 de la noche, robó el cuerpo de Santa Lucía de la iglesia de San Jeremías, de Venecia. Al salir corriendo, los bandidos dejaron parte del botín: la cabeza de la santa, un dedo y la máscara de plata que le cubría el rostro. El cuerpo fue recuperado y devuelto a la Iglesia unos meses después ${ }^{5}$.

La fiesta de Santa Lucía se celebra en diversas ciudades del mundo, y, durante la Edad Media, la festividad coincidía con el solsticio de invierno. Los vikingos conocieron la historia de Lucía y, como eran cristianos, llevaron su imagen a Suecia. La celebración de Santa Lucía representa una tradición importante para ellos, pues simboliza la esperanza y la luz en épocas de oscuridad. Así, en Estocolmo, desde aproximadamente 1899, en la mañana del 13 de diciembre, las niñas se visten de "Lucía», con un vestido blanco con una corona de siete velas encendidas en la cabeza, y los niños llevan un sombrero puntiagudo decorado con estrellas (stjärngossar). Esto es porque se cuenta que, durante una hambruna en Siracusa, la gente de la ciudad se reunió en la catedral para rezar y pedirle ayuda, y Lucía llegó vestida de blanco con un halo de velas en su cabeza, en dos barcos cargados de trigo. E⿰亻⿻一丿乛 de la fiesta de Santa Lucía, en Suecia, además, se hornean pastelitos, a los que llaman bollos de Lưcía (Lussebulle), los cuales tienen forma de ojos, y sêlos comen después de cantar canciones tradicionales. La fiesta termina con la elección de una de las niñas cemo "Reina de Lucía de Suecia» (Sveriges Lucia). Celebraciones similares se hacen en Dinamairca, Finlandia y Noruega, y son una de las traiciones más populares de aquellos países ${ }^{4}$. En Baza, ciudad siturada en el noreste de la provincia de Granada, en Andalucia, se celebra con el encendido de fogatas durante la noche del 12 al 13 de diciembre, haciendo remembranza de que Lucía fue quemada en la hoguera En la localidad de Hacinas, en Burgos, es el tercer domingo de septiembre que celebran Santa Lucía con Ena romería popular en los alrededores de la ermita de Santa Lucía ${ }^{1,2}$.

\section{Conclusión}

El primer vestigio del culto a Lucía fuera de Sicilia se encuentra en la ciudad de Rávena, Italia, en la iglesiä de San Apolinar Nuevo, donde aparece una primera representación incluida en el desfile de las vírgenes ${ }^{1,20} \mathrm{Su}$ figura se representa como a casi todas las vírgeñes, vestida con una túnica con diferentes adornos en la cabeza: corona, diadema, flores, velo, o al descubiërto, según la costumbre romana. En la iconografía medieval, Lucía es representada de diversas formas (Tabla 2$)^{6}$. Habitualmente, con una espada o un cuchillo queje le atraviesa el cuello (referente a la lanza que le atravesó la garganta), que puede acompañarse de rayos dêluz irradiando de la herida del cuello, un libro (distintivo de sabiduría), la palma del martirio (símbolo común a todos los santos mártires), un buey pisoteado bajo sus pies (relativo a los bueyes que no pudieron moverla), llamas en los pies (relacionado al martirio en la hoguera), occon una la lámpara encendida, el cirio en la mano o losâos ojos en un plato dorado, lo que refleja la devoción pêpular hacia ella como protectora de la vista ${ }^{5}$. Se han dedicado hospitales y clínicas a su nombre en todo el muñdo. Lucía, como vimos, además de ser venerada porporoblemas oculares, se señala que salvó en varias ocassiones a Siracusa en momentos de hambre, terremotos y guerras, y que ha intervenido también en otras ciudades como Brescia, en Italia, pues, gracias a su intercesión, fue liberada de una gran miseria. Los devotos de Sânta Lucía, como agradecimiento de curaciones, le ofrecen, como ofrenda en cumplimiento de una promesa o en 
Tabla 2. Principal Iconografía de Sana Lucía

\begin{tabular}{|c|c|c|c|}
\hline Autor & Lugar/país & Pintura & న్ \\
\hline Anónimo & Museo de Arte de Cataluña, Barcelona, España & \multicolumn{2}{|c|}{$\begin{array}{l}\text { Santa Lucía de Mur, ciclo de su vida. Pintura } \\
\text { sobre tabla, procedente de la iglesia de Santa } \\
\text { Lucía de Mur, c. } 1300\end{array}$} \\
\hline Anónimo & Museo del Prado. Madrid, España & Santa Lucía. Óleo sobre tabla & $\stackrel{0}{0}$ \\
\hline $\begin{array}{l}\text { Altichiero da Zevio } \\
\text { (c.1330-c.1393) }\end{array}$ & Oratorio di San Giorgio, Padua, Italia & \multicolumn{2}{|l|}{$\begin{array}{l}\text { Ciclo de Santa Lucía. Pintura mural al fresco, } \\
1379-84\end{array}$} \\
\hline $\begin{array}{l}\text { Maestro de Estimariú (activo } \\
\text { entre } 1360 \text { y 1380) }\end{array}$ & Museo Nacional del Prado, Madrid, España & \multicolumn{2}{|l|}{$\begin{array}{l}\text { Retablo con las historias de la vida de Santž } \\
\text { Lucía. Pintura sobre tabla, s. XIV }\end{array}$} \\
\hline Bernat Martorell (1400-?) & $\begin{array}{l}\text { Museo Nacional de Arte de Cataluña, Barcelona, } \\
\text { España }\end{array}$ & \multicolumn{2}{|c|}{$\begin{array}{l}\text { Martirio de Santa Lucía (en la hoguera). Temple } \\
\text { sobre tabla, 1435-1440 }\end{array}$} \\
\hline Anónimo & Capilla de Montalto Dora, Turín, Italia & \multicolumn{2}{|c|}{$\begin{array}{l}\text { Santa Margarita, Santa Librada y Santa Lucla } \\
\text { (esta última con los ojos en un plato). Pintura } \\
\text { mural al fresco, s. XV }\end{array}$} \\
\hline $\begin{array}{l}\text { Andrés de Melgar (c. 1500- } \\
\text { 1554) }\end{array}$ & $\begin{array}{l}\text { Museo Nacional de Arte de Cataluña, Barcelona, } \\
\text { España }\end{array}$ & \multicolumn{2}{|c|}{$\begin{array}{l}\text { Santa Apolonia, Santa Lucía (con los ojos eñ } \\
\text { un plato) y Santa Bárbara. Óleo sobre tabla } \\
1530-1537\end{array}$} \\
\hline $\begin{array}{l}\text { Jacobello del Fiore } \\
\text { (c. 1370-1439) }\end{array}$ & Museo Cívico, Fermo, Italia & \multicolumn{2}{|l|}{$\begin{array}{l}\text { Eutiquia y Santa Lucía ante la tumba de Santa } \\
\text { Águeda, } 1410\end{array}$} \\
\hline Cosmè Tura (1430-1495) & Roma & $\begin{array}{l}\text { Santa Lucía y Santa Eutiquia en la tumba de } \\
\text { Santa Águeda } 1480-1489\end{array}$ & $\operatorname{de} \frac{8}{8}$ \\
\hline $\begin{array}{l}\text { Francisco de Zurbarán } \\
\text { (1598-1664) }\end{array}$ & Museo de Bellas Artes de Chartes, Francia & Santa Lucía. Óleo sobre lienzo, 1636 & $+\frac{0}{c}$ \\
\hline Lorenzo Lotto (1480-1553) & $\begin{array}{l}\text { Pinacoteca civica e galleria di arte contemporanea, } \\
\text { Palazzo Pianetti, Jesi, Italia }\end{array}$ & Santa lucía ante al juez, 1523-1532 & 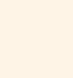 \\
\hline $\begin{array}{l}\text { Antonio José Estruch Martínez } \\
\text { (1835-1907) }\end{array}$ & & Santa Lucía & 잉 \\
\hline Pietro Lorenzetti & Frole Rovinate de Florencia & Tabla Santa Lucía, s. XIV & $\frac{0}{2}$ \\
\hline Niccolò di Segna (? -1348) & Walters Art Museum, Baltimore, EE.UU. & Santa Lucía & $\frac{2}{2}$ \\
\hline $\begin{array}{l}\text { Domenico di Pace Beccafumi } \\
\text { (1484-1551) }\end{array}$ & Pinoteca Nazinale, Siena, Italia & Santa Lucía & ¿ \\
\hline Paolo Veronese (1528-1588) & National Gallery of Art, Washington DC, EE.UU. & $\begin{array}{l}\text { El martirio y última comunión de Santa Luc } \\
1582\end{array}$ & 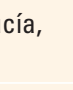 \\
\hline $\begin{array}{l}\text { Giovanni Battista Tiepolo } \\
(1696-1770)\end{array}$ & Iglesia de los Santos Apóstoles, Venecia, Italia & \multicolumn{2}{|l|}{ Última comunión de Santa Lucía. Óleo sobre } \\
\hline $\begin{array}{l}\text { Francesco del Cossa (1436- } \\
\text { 1477) }\end{array}$ & National Gallery of Art Washington, DC, EE.UU & \multicolumn{2}{|l|}{$\begin{array}{l}\text { Santa Lucía. Temple sobre panel de álamo, } \\
\text { 1430-1477 }\end{array}$} \\
\hline $\begin{array}{l}\text { Giovanni di Bartolommeo } \\
\text { Cristiani (1340-1398) }\end{array}$ & Museo Metropolitano de Arte, Nueva York, EE.UU. & \multicolumn{2}{|l|}{$\begin{array}{l}\text { Santa Lucía y su madre en el santuario de } \\
\text { Santa Águeda }\end{array}$} \\
\hline $\begin{array}{l}\text { Giovanni di Bartolommeo } \\
\text { Cristiani (1340-1398) }\end{array}$ & Yale University Art Gallery, Connecticut EE.UU. & Santa Lucía entronizada, c. $1347-1400$ & $\stackrel{0}{\stackrel{0}{c}}$ \\
\hline $\begin{array}{l}\text { Leandro (dal Ponte) Bassano } \\
\text { (1557-1622) }\end{array}$ & Iglesia de San Giorgio Maggiore, Venecia, Italia & El Martirio de Santa Lucía, 1596 & 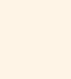 \\
\hline $\begin{array}{l}\text { Michelangelo Carvaggio } \\
(1571-1610)\end{array}$ & Basilica di Santa Lucia al Sepolcro, Siracusa, Italia & El entierro de Santa Lucía,1608 & $\frac{\mathrm{U}}{\bar{c}}$ \\
\hline $\begin{array}{l}\text { Carletto Veronese (c. } 1570- \\
\text { c.1596), }\end{array}$ & Museo del Prado. Madrid, España & $\begin{array}{l}\text { La Virgen y el Niño con Santa Lucía y un } \\
\text { Mártir. Óleo sobre lienzo }\end{array}$ & Santo \\
\hline Carlo Crivelli (c.1435-c.1495) & National Gallery, Londres, Inglaterra & Santa Lucía, c.1430/5-1494 & ट \\
\hline Agostino Ciampelli (1565-1630) & $\begin{array}{l}\text { Collection British Optical Association Museum, } \\
\text { Londres, Inglaterra }\end{array}$ & Santa Lucía. Óleo sobre lienzo & 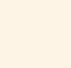 \\
\hline
\end{tabular}


agradecimiento por un favor recibido, ojos de oro o plata y una oración que incluye las palabras: «llenos de confianza a ti acudimos pidiéndote la gracia de que la nuestra se mantenga sana y que el uso que hagamos de nuestros ojos sea siempre para bien de nuestra alma...» ${ }^{4}$

\section{Conflicto de intereses}

Los autores declaran que no tienen ningún conflicto de intereses.

\section{Bibliografía}

1. González-Hernando I. The legend of Lucy of Syracuse. Consultado abril4, 2020. Disponible en: https://www.eldrbarry.net/mous/saint/luc_bro. pdf

2. North W. The Life and Prayers of Saint Lucy of Syracuse. Wyatt North Publishing. 2010.

3. Ortiz-Hidalgo C. Águeda de Catania: santa patrona de las enfermeđades de la glándula mamaria. Gac Med Mex. 2011;147:437-43.

4. Goes F. Saint Lucy and other saints of the blind. En: The eye in history. New Dehli: Jaypee-Highlights Medical Publishers; 2013. p. 306-09.

5. Arias J. El cuerpo momificado de santa Lucía, robado en Venecia a punta de pistola. Disponible en: https://elpais.com/diario/1981/11/10/sociedad/374194803 850215.html

6. Barbón-García JJ, Álvarez-Suárez ML. Santa Lucía a través de la Đintura. Arch Soc Esp Oftalmol. 2003:78:689-92. 